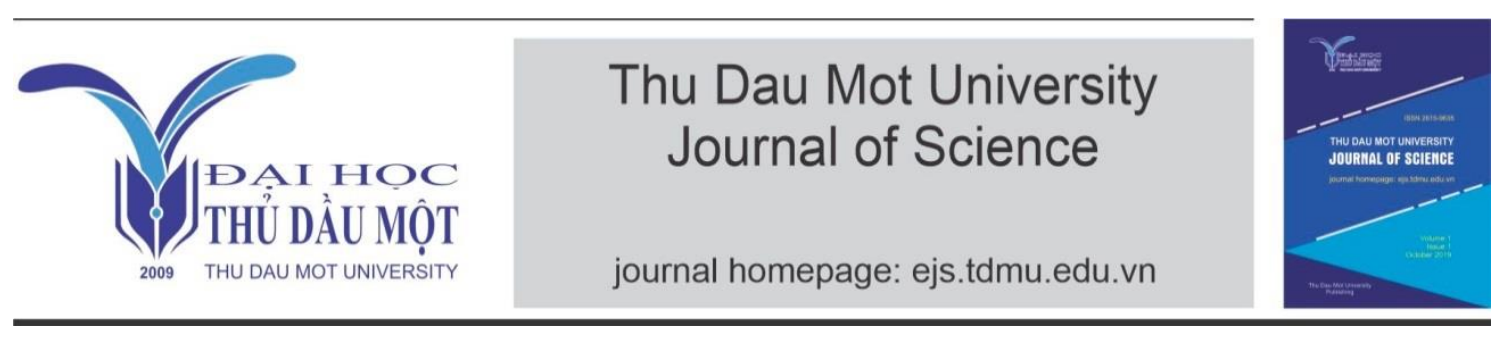

\title{
An empirical research on achieving success with Lean
}

\author{
by Tôn Nguyễn Trọng Hiền (ĐH Văn Lang) \\ Gareth Jones (ETP ion detect company, Australia)
}

\begin{abstract}
Article Info: Received 22 Mar. 2021, Accepted 2 June 2021, Available online 15 June 2021
Corresponding author: hien.tnt@vlu.edu.vn

https://doi.org/10.37550/tdmu.EJS/2021.02.203
\end{abstract}

\begin{abstract}
Several companies apply lean manufacturing however the implementation in organizations is not always successful. One of the difficulties is deciding which of the lean approach to avoid the failure; therefore this paper reviews the key concepts and attributes of the lean paradigm, and identifies how they can be applied to ETP's current operational practices. The study results show a successful lean transformation case study. Practically, this is a comprehensive guideline for practitioners to implement Lean in their organizations to make better decisions.
\end{abstract}

Keywords: lean manufacturing, lean transformation, lean success, framework

\section{Introduction}

An award-winning, and leading manufacturer of product solutions for mass spectrometry, ETP Ion Detect's global presence is supported by its technical and distribution networks located throughout the Americas, Europe, Japan, Asia Pacific, India, China, and the Middle East. Its primary R\&D and manufacturing divisions, situated in Sydney, Australia supplies approximately 20,000 products a year that generate an annual turnover of AU\$20 million. ETP's current market position has derived from the overall Mass Spectrometry (MS) market. A method used to measure the characteristics of specific molecules, MS machines ionize molecules of a chemical composite and then categorizes each according to their mass to charge ratio. The global 
mass spectrometry market was valued at US $\$ 4,598$ million in 2016 and is estimated to reach US $\$ 7,922$ million by 2023 . Based on an average cost of a multiplier being approximately $3 \%$ of the overall cost of an average MS device, the ion detection market value can thus be guesstimated at approximately US\$140 million. The market can be subdivided into four segments by applications (Research, Industrial, Clinical, and Government), of which, ETP currently operates within the research segment only, and occupies no presence within any of the others to date.

The research segment is a low-volume, high-value market that is continually growing, and ETP is believed to be amongst the top two companies currently dominating this area. With competition from two major organizations (Photonis and Hamamadzu), as well as a growing presence from smaller providers, ETP recognizes a need to venture into with newer segments (Industrial and Clinical) of the MS market. However, despite the identification of new markets, the company must be able to sustainably up-scale its capacity, without compromising both current and future quality levels.

Traditionally, a company gained its competitive advantage by owning a distinctive trait that positioned it in a superior business position, specifically, by being cheaper or different to its competitors. The motor vehicle industry experienced this and the application of models adapted from other industries, such as Henry Ford's utilization of the Chicago Slaughter House operations model in the 1920's, has arguably driven several shifts in production practices (craftsmanship to mass production) (Womack, et al., 1990). The efforts of quality guru such as Shewhart, Deming, Juran, Crosby and Ishikawa, later demonstrated how the deployment of continuous improvement initiatives were crucial in attaining superior quality levels, leading to customer satisfaction and thus subsequently acquiring a competitive advantage. Coupled with the evolving prominence of generating even cheaper products and with increased customer knowledge and demands, lean production became the new direction following the success of Toyota's Production System (TPS), as highlighted by the IMVP World Assembly Plant Survey (Womack et al., 1990).

After years of Lean, there is no evidence of any lasting success. Although there are many potential benefits to adopting lean, not all companies will be successful (Pearce and Pons, 2013; Raweewan and Kojima, 2020), the success rate is very low (Chaple et al., 2018), "no more than $10 \%$ of firms succeeded in implementing lean" (Zhang et al., 2017). It is said that failure may come from not doing the right steps and not understanding nature of lean (Miina, 2012; Raweewan and Kojima, 2020). Miina (2012); Jacob and Kothandaraman (2021) indicate that success or failure of lean in achieving lean strongly depends on companies approach to it. There are many approaches to reach success of lean. Therefore, this paper will evaluate the potential of 
'Lean Thinking' for improving ETP's current level of operational performance, by critically analysing the key principles, methodologies, tools and techniques associated with the Lean paradigm whilst also considering its fit in to ETP's business and manufacturing contexts.

\section{Literature review}

Many definitions of lean have existed since its inception, with the hard and fast version being Womack and Jones' "doing more and more with less and less", which Bicheno \& Holweg (2016) explain also relates to the concept of productivity (outputs / inputs). However, John Darlington' (2009) definition of lean as “... [the use of available capacity in such a way as to] make services and products flow as close to real demand as possible and keep it flowing from one value adding step to the next, with no delay", is arguably the most fitting to describe the modern paradigm.

It was soon realized that there was a complete lack in ability to identify and understand the subsystems involved. Echoing the visual perception principles of Gestalt psychologist Kurt Koffa, who famously stated the whole is other than the sum of its parts. It must be realized that complex problems (deeper root causes) involve the interconnected sets of elements (steps/processes/people/enterprises) and the relationships between those elements, as opposed to the individual nature of the elements themselves. Thus, Womack and Jones (1996) book 'Lean Thinking' attempts to eradicate all the prior failures by providing a greater level of deliberation towards the 'whole' process. It now considers the flow of value, and the roles that firms, functions and careers play during the development of a product (Womack \& Jones, 2003). They defined their initial work into five principles, to be implemented in a 'Continuous Improvement' (Kaizen) cycle, replicating of Deming's PDCA model. Applying the principles to build a culture of continuous improvement depends on the alignment of three key areas; People, Process and Purpose. These key concepts and attributes, and how they work together as a complete business system is now presented in a new 'Lean Enterprise' model. Therefore, many lean journeys have not been as successful or sustainable, traditional waste reduction tool-based Lean approach is wrong (Hines et al., 2018. In this study we would like to convince lean as a lifelong journey to build a culture of continuous improvement based on rigorous use of core systems.

\section{Lean evaluation}

The ETP Company started to apply lean in the early 2000s but actually the results were not as expected, the profit from the lean plan did not yield a positive result. It is realized 
that although there are many approaches to the Lean transformation and no single right way of doing so, it should be tailored to the specific business issues, the culture and mind-set of each organization. So, the Lean Transformation Framework allows organizations to better achieve a Lean transformation, by considering its application. Furthermore, Womack and Jones (2003) ensure "a specific sequence of steps and initiatives produce the best results", outlining within a detailed, five-year action plan (Table 1).

TABLE 1. The Lean Transformation Timeframe (Womack \& Jones, 2003)

\begin{tabular}{|c|c|c|}
\hline Phase & Specific steps & The frame \\
\hline \multirow[t]{6}{*}{ Get started } & Find a change agent & First six months \\
\hline & Get lean knowledge & \\
\hline & Find a lever & \\
\hline & Map value streams & \\
\hline & Begin kaikaku & \\
\hline & Expand you scope & \\
\hline \multirow[t]{6}{*}{ Create a new organisation } & Reorganise by product family & Six months through year two \\
\hline & Create lean function & \\
\hline & Devise a policy for excess people & \\
\hline & Devise a growth strategy & \\
\hline & Remove anchor-draggers & \\
\hline & Instill a "perfection" mind-set & \\
\hline \multirow[t]{6}{*}{ Install business system } & Introduce lean accounting & Years three and four \\
\hline & Relate pay to firm performance & \\
\hline & Implement transparency & \\
\hline & Initiate policy deployment & \\
\hline & Introduce lean learning & \\
\hline & Find right-sized tools & \\
\hline \multirow[t]{3}{*}{ Complete the transformation } & $\begin{array}{l}\text { Apply these steps to your suppliers/ } \\
\text { customers }\end{array}$ & By the end of year five \\
\hline & Develop global strategy & \\
\hline & Transition from top-down & \\
\hline
\end{tabular}

The key is to begin by searching for able leaders who hold the right knowledge to drive dramatic changes within the value stream. Then to expand the scope of change, to include the entire organization and its business procedures, and once fully grasped and in control, further broadening value to include changes within external entities (suppliers and customers) to augment the whole (Womack \& Jones, 2003). However, considering the many difficulties and questions posed by companies attempting lean, Hines \& Taylor (2000) have devised a simple 'how to', six-stage guide (Figure 1), whilst also advising on where, when and who to involve during the transformation exercise (Figure 2). 


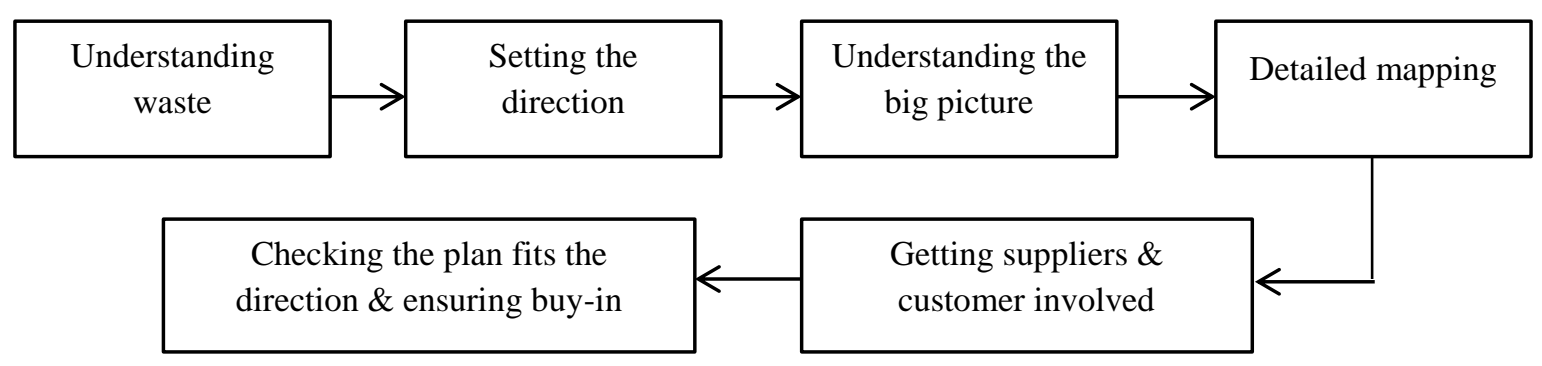

Figure 1. Lean Thinking Enterprise Model (Hines \& Taylor, 2000)

\begin{tabular}{l|l|l|l|}
\hline Workbook focus $\downarrow$ & Senior managers $\downarrow$ & Line managers $\downarrow$ Wider workforce \\
\hline What is Lean? & Lean thinking & \\
\cline { 2 - 2 } & Understanding waste \\
\hline Focusing the Change & Setting the direction & \\
\hline Mapping Things Out & Understanding the big picture \\
\hline & & Detailed mapping \\
\hline Will It Work? & Checking the plan fits the direction \& ensuring buy-in \\
\hline Help! & Further sources of help \\
\hline
\end{tabular}

Figure 2. Employee involvement during the lean transformation (Hines \& Taylor, 2000) As evidenced by the history of failures in organization attempting to replicate TPS, there is clearly no magic recipe on how to apply lean thinking, since every situation differs and attempting to emulate another exactly, does not work. Organization should understand that Toyota realized this early on, as they too initially tried replicating the likes of Ford and GM's production methodology, and failed miserably. The famous quote "there is no losing, you either win or learn", used by such leaders as Nelson Mandela and Carlos Gracie Sr. (one of the primary developers of Brazillian Jui Jitsu) signifies the kind of culture required to achieve success. We conform to this mindset by explaining an organization ability to create positive change must come from individuals able to embrace failure if/when they occur what we see holding many organizations back is the fact that they don't have a group of capable people leading the transformation. The capability to lead change can only be learned by doing, and by failing a few times. Furthermore, we believe the key to successfully implementing lean thinking, is to study the beginnings of Toyota's journey, rather than their current 
strategies. He explains it was their prior work and struggles, coupled with their continuous learning mindset that contributed largely to Toyota's success.

There are several reasons as to why our lean implementation framework is suitable to ETP's organization. Beyond the external battle with higher levels of competitor presence within the research segment of the market, and with the objective to break in to new sectors. The company suffers with an institutionalized culture where only those in management can provide solutions, and with little appreciation for the knowledge and talent possessed by all other employees. The organization seems to be continually experiencing the following issues, also:

\section{Late Customer deliveries}

There is a constant battle to ship products out on time, to the dates originally promised to the customers. Which, leads to the same frustrating questions being asked by the customer service representative, weekly: "Why can't we ship our products on time?", "What has gone wrong this time?", "What new shipping date can I provide to the customer?".

Table 2 displays a recent week's delivery record, showing an overall adherence capability of $85 \%$. Upon further investigation, model ETT has only a 50\% adherence achievement that is based on a quantity of only two requiring being shipped. This is a pretty inexcusable result, considering the tiny number ordered by the customer.

TABLE 2. ETP Weekly on-time deliveries (W/C 9-04-2018)

\begin{tabular}{|l|c|c|c|c|}
\hline \multicolumn{5}{|c|}{ ETP Weekly On Time Delivery to ETP's Promise Date } \\
\hline Part Type & $\begin{array}{c}\text { Qty Promised } \\
\text { (incl Overdues) }\end{array}$ & $\begin{array}{c}\text { Actual Qty Shipped } \\
\text { this Week }\end{array}$ & $\begin{array}{c}\text { Qty Shipped to Promise } \\
\text { Incl. early shipments }\end{array}$ & Adherence \% \\
\hline ETB & 140 & 99 & 139 & $99.29 \%$ \\
\hline ETC & 12 & 12 & 12 & N/A \\
\hline ETG & 140 & 138 & 128 & $100.00 \%$ \\
\hline ETH & 13 & 13 & 0 & $91.43 \%$ \\
\hline ETL & 185 & 109 & 136 & $0.00 \%$ \\
\hline ETM & 2 & 1 & 1 & $53.51 \%$ \\
\hline ETT & & & & $50.00 \%$ \\
\hline ETX & 492 & 372 & 416 & N/A \\
\hline Total & & & & $84.55 \%$ \\
\hline
\end{tabular}

Further, reviewing over a two-year period (Figure 3) and based on a 95\% target figure, there has been a considerable decline in on-time delivery achievements since late 2016. The lowest being at approximately 28\% during August 2017, and despite a slight upward trend since, the average rolling figure is currently standing at around $66 \%$. Thus, leading to considerable improvements to be gained as customer satisfaction is one of the key requirements and indicator of performance. 


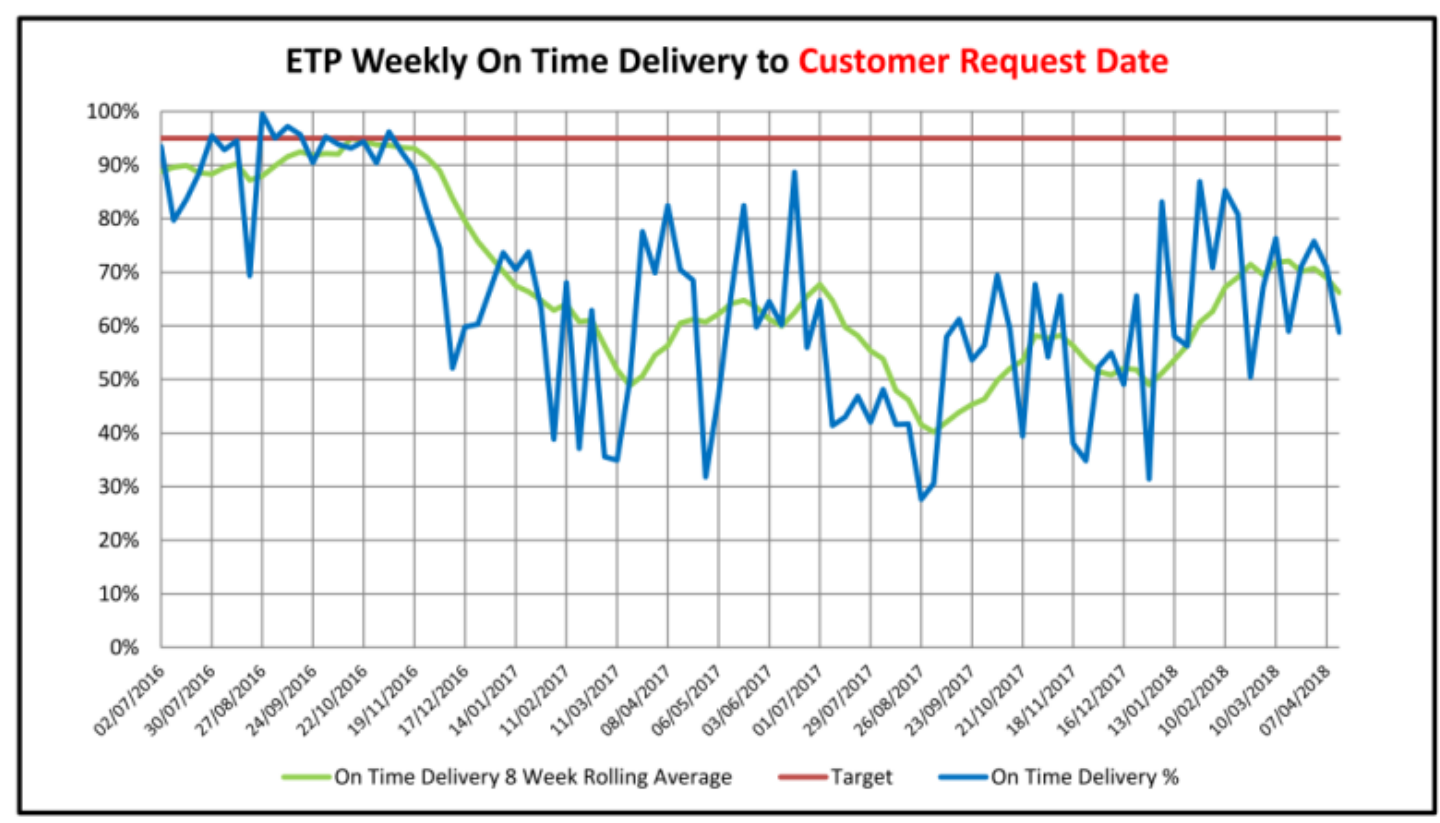

Figure 3. ETP Weekly on-time deliveries (20-month period)

\section{Test failures}

One of the major bottlenecks of the value stream within ETP, and thus a contributing factor to the continual delivery failures previously discussed, is the testing of its products. As displayed within Table 3, a recent week's first pass yield averaged at 84\% and when considering the retesting of those failed products, the average test yield decreased further to $81 \%$.

TABLE 3. Testing Performance (W/C 9-04-2018)

\begin{tabular}{lcc}
\hline & \multicolumn{2}{c}{ Testing performance } \\
& $1^{\text {st }}$ pass rate & Test yield \\
ETT & $92.86 \%$ & $93.33 \%$ \\
ETH & $83.52 \%$ & $83.16 \%$ \\
ETM & $80.91 \%$ & $77.37 \%$ \\
ETC & $75.00 \%$ & $80.00 \%$ \\
ETB & $90.00 \%$ & $78.70 \%$ \\
Total & $84.28 \%$ & $80.65 \%$ \\
\hline
\end{tabular}

Although there have been signs of improvement over a 16-month period (Figure 4), it doesn't seem to be very stable. The lowest recording was approximately $65 \%$ (April 2017), however, the rolling average doesn't seem to be much higher (75\%) and despite it rising to around $85 \%$ of late, there has been little evidence of it breaking $90 \%$. The added issue for the company is that they conduct $100 \%$ testing on all products, many require retesting and a few multiple times over. This provides a heavy burden on to the testing operators as well as the process itself, resulting in much blame without any evidence of analysis (FTA, 5 Why's, cause and effect) being practiced. This shows a 
lack in understanding and confidence in both design and production processes, which results in substantial quarantined stock that provides no value to both customer and company.

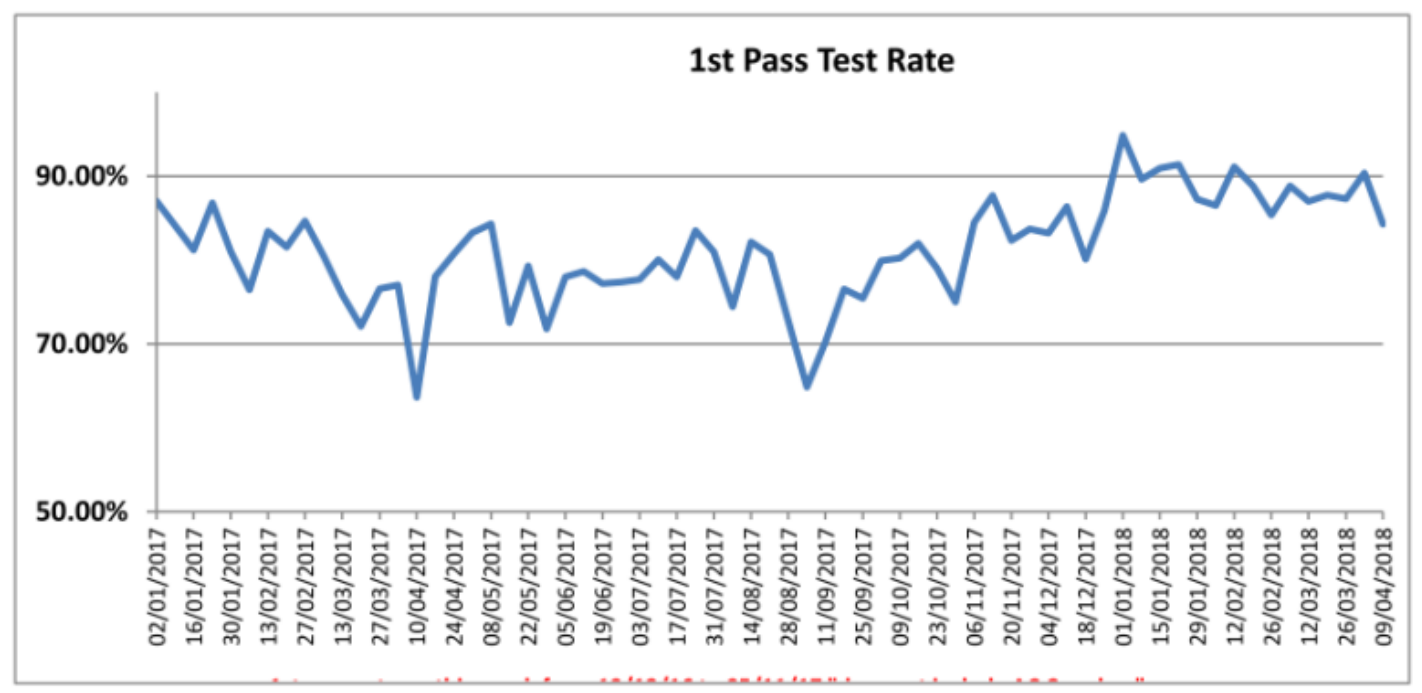

Figure 4. First pass yield

\section{Backlog of quarantined items}

The level of quarantined items is quite erratic, as shown within Figure 5. Ranging from a weekly quantity of 31 to 88 items creates a vast amount of strain on production, as resource are required to investigating and resolve the issues that lead to the products failing. Which, then prompts a need for re-work orders to be issued and as there is no dedicated re-work area, they must be scheduled back in to the normal production process flow. At the end of the 2017 financial year, there was an AU\$800,000 value on backlogged items the company was unable to ship on to its customers, due to being held under quarantine. Unfortunately, much of the quarantined stock is irretrievable and ends up being scrapped which, resulted in an approximate AU\$200,000 loss in 2017.

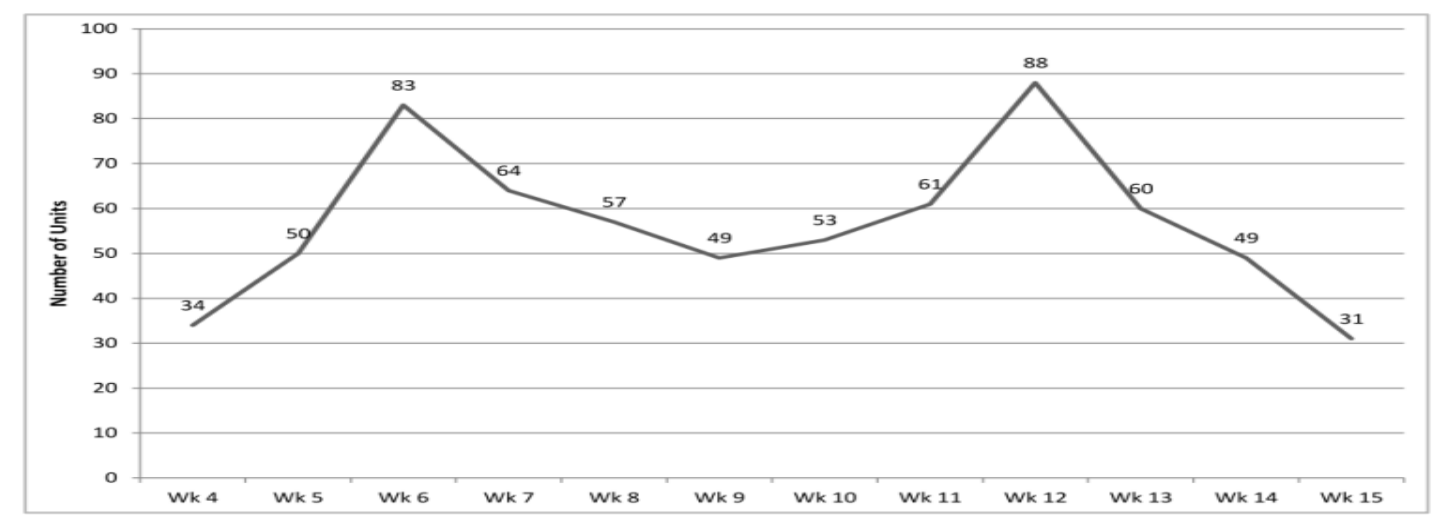

Figure 5. Three-month quarantined stock figures (2018) 


\section{Capacity issues}

The impact of having quarantined items is the inability to sustain current work orders and thus current product output demands. Graphs 4 and 5 display a considerable disparity between the number of completed work orders vs. those left open within parts preparation. Only around $40 \%$ of the total open work orders are being completed on a weekly basis, compared with $50 \%$ being completed within the clean room. In terms of finished goods, only 55\% are being completed vs. those left overdue. Comparing the above figures to the average output of between 8 and 10 units per employee, per week, highlights an inadequate application of the Takt time theory and thus, provides an indication of building for stock, as opposed to relying on the pull of customer orders.

\section{Inventory Issues (Batch \& Que production)}

Table 3 and Graph 9 display how much waste is held in stock, specifically equating to approximately $300 \%$ more than is required from customer demand. This also creates added waste in floors pace and increases the risk of hidden defective parts being held and thus, being unactioned in time.

All the above can be considered Muda, however, the company falls victim to many more wastes, such as the following:

- Incomplete/inadequate information (drawings/work instruction)

- Long project transfer cycles

- Inefficient processes (inc. administrative)

- Inefficient communication

- Continual reactive responses to issues

- Variations in product quality

- Inadequate tooling

- Substantial Scrap costs

- Production Downtimes

None of which will ever add any value, and proves that ETP are currently stuck between archaic craftsmanship and mass-production (batch \& que) paradigms. Therefore, by transforming into a Lean Enterprise and converting ETP's operations into continuous flow with effective pull by the customer, Womack \& Jones (1996) advise the following simple rules of thumb can be achieved:

- Double labour productivity throughout the whole system.

- Cutting production throughput times by 90 percent.

- Reducing inventories in the system by 90 percent as well.

- Errors reaching the customer and scrap within the production process are typically cut in half,

- $50 \%$ reduction in work-related injuries. 
- $50 \%$ reduction on time-to-market for new products.

- Wider varieties of products can be offered at very modest additional cost.

- Capital investments will be very modest, even negative, if facilities and equipment can be freed up and sold.

This is the kaikaku bonus, released by the initial, radical realignment of the value stream. Then by continuously implementing kaizen in a bid to reach perfection can typically double productivity, and halve inventories, errors, and lead times again within a two to three-year period. Thus, combining the two philosophies, can produce endless improvements (Womack \& Jones, 2003). However, considering it from a practical perspective, the Manufacturing Advisory Service (MAS) in the UK suggest the average results for companies in many differing industries and of different sizes implementing lean over a period of several years, are as follows: Delivery $+26 \%$, Stock Turns $+33 \%$, Productivity $+25 \%$, Scrap $-26 \%$, Space $-33 \%$.

\section{Conclusion}

This paper identifies the key concepts and attributes of the Lean paradigm, and how they can be applied to ETP's current operational practices. The lean thinking paradigm fits well in to the company's current state, as it provides many more benefits over any difficulty posed by its implementation. Thus, by applying the improvement to the known quantities figures highlighted within the evaluation section, ETP could expect the following impact on its operational performances (Table 4):

TABLE 4. Lean Implementation Improvement Figure

\begin{tabular}{lrr}
\hline Operational Aspects & $\begin{array}{r}\text { Current } \\
\text { Performance }\end{array}$ & $\begin{array}{r}\text { Potential Lean } \\
\text { Performance }\end{array}$ \\
\hline Turnover & $\$ 20 \mathrm{~m}$ & $\$ 30 \mathrm{~m}-\$ 40 \mathrm{~m}$ \\
Delivery & $66 \%$ & $90 \%$ \\
1 st Pass Test & $75 \%$ & $90 \%+$ \\
Quarnetined Stock & $10 \%$ & $5 \%$ \\
Capacity & $400 \mathrm{p} / \mathrm{w}$ & $600-800 \mathrm{p} / \mathrm{w}$ \\
Labour Productivity & $10 \mathrm{pe} / \mathrm{pw}$ & $15-20 \mathrm{pe} / \mathrm{pw}$ \\
Inventories & $300 \%$ & $30 \%$ \\
Scrap & $\$ 200 \mathrm{k}$ & $\$ 100 \mathrm{k}-150 \mathrm{k}$ \\
Time to market & $1-2 y e a r s$ & $0.5-1$ years \\
\hline
\end{tabular}

Furthermore, it is possible to achieve even greater levels of stability and improvements by combining Lean with Theory of Constraints (TOC). Combining Lean with TOC synergistically can provide many added benefits to those already highlighted. TOC integrates well in between steps two and three of the five-step lean enterprise 
framework. Here, it can enhance the lean effort by not only focusing on where it will add the greatest benefit (the system constraint), but also at those bottlenecks deemed as infeasible to eliminate.

\section{References}

Bicheno, J. \& Holweg, M. (2016). The Lean Toolbox: a handbook for lean transformation. Buckingham: PICSIE.

Chaple, A., Narkhede, B., Akarte, M., \& Raut, R. (2018). Modeling the lean barriers for successful lean implementation: TISM approach. International Journal of Lean Six Sigma, 12(1), 98-119.

Hines, P. \& Taylor, D.(2000). Going lean. 1 ed. Cardiff: Lean Enterprise Research Centre

Hines, P., Taylor, D., \& Walsh, A. (2018). The Lean journey: have we got it wrong?. Total Quality Management \& Business Excellence, 31(3-4), 389-406.

Jacob, S., \& Kothandaraman, K. (2021). Analysis, an Anathema: Is That a Fervent Diatribe of Lean?. Lean Manufacturing [Working Title].

Miina, A. (2012). Lean Problem: Why Companies Fail with Lean Implementation? Management, 2(5), 232-250.

Pearce, A., \& Pons, D. (2013). Implementing Lean Practices: Managing the Transformation Risks. Journal of Industrial Engineering, 1-19.

Raweewan, M., \& Kojima, F. (2020). Digital Lean Manufacturing - Collaborative UniversityIndustry Education in Systems Design for Lean Transformation. Procedia Manufacturing, 45, 183-188.

Thomas, A., Dorrington, P., Costa, F., Loudon, G., Francis, M., \& Fisher, R. (2017). Organizational learning capability in SMEs: An empirical develop

Womack, J. P. \& Jones, D. T. (1996). Lean Thinking. First ed. New York: Simon and Shuster.

Womack, J. P. \& Jones, D. T. (2003). Lean thinking: banish waste and create wealth in your corporation. eBook ed. London: Simon \& Schuster UK Ltd.

Womack, J. P., Jones, D. T. \& Roos, D. (1990). The Machine that Changed the World. 1st ed. New York, United States: Simon \& Schuster Ltd.

Zhang, L., Narkhede, B., \& Chaple, A. (2017). Evaluating lean manufacturing barriers: an interpretive process. Journal of Manufacturing Technology Management, 28(8), 10861114. 